\title{
Establishment of plant regeneration system for young leaf explants of Cassia mimosoides
}

\author{
Yali Yang ${ }^{1,2}$, Peiting He ${ }^{1}$, Shengyuan Zhang ${ }^{1,2}$, Dadu Lin $^{1}$, Zhentao Liu ${ }^{1}$, Lubin Zhang ${ }^{1,2}$, Ming Zhai ${ }^{*}$, and Ying Liu ${ }^{3 *}$ \\ ${ }^{1}$ School of Medicine, Jiaying University, Meizhou 514031, China \\ ${ }^{2}$ Guangdong Provincial Key Laboratory of Conservation and Precision Utilization of Characteristic Agricultural Resources in \\ Mountainous Areas, Meizhou 514031, China \\ ${ }^{3}$ College of Coastal Agricultural Sciences, Guangdong Ocean University, Zhanjiang 524088, China
}

\begin{abstract}
In the present study, a plant regeneration system was established by using young leaf explants from aseptic seedlings of Cassia mimosoides. The results showed that when the explants were inoculated on the $1 / 2 \mathrm{MS}$ medium contained $2.0 \mathrm{mg} / \mathrm{L} 6-\mathrm{BA}$ and $0.5 \mathrm{mg} / \mathrm{L}$ NAA, high rate of callus induction and good growth status of adventitious bud, and the highest number of buds were obtained. Further studies conclusively suggested that IBA could not promote root formation effectively, but the root regeneration could be induced by NAA. However, although the rooting of regeneration buds could be induced when adventitious buds were placed into $1 / 2 \mathrm{MS}$ medium supplemented with $0.5 \mathrm{mg} / \mathrm{L}$ NAA, the rate of rooting was reduced, and the roots became shorter. Therefore, the best medium for adventitious bud regeneration using young leaf as explants in C. mimosoides was $1 / 2 \mathrm{MS}$ medium contained $2.0 \mathrm{mg} / \mathrm{L} 6-\mathrm{BA}$ and $0.5 \mathrm{mg} / \mathrm{L}$ NAA, and the best rooting medium was $1 / 2 \mathrm{MS}$.
\end{abstract}

\section{Introduction}

Cassia mimosoides Linn., belongs to the genus of Cassia in the legume family [1]. It is mainly distributed in the provinces of Guangdong, Guangxi, Sichuan, Hunan and Fujian in China. It has the effect of clearing away heat and detoxifying, invigorating spleen and dampness, and purging, mainly used for treating many diseases such as jaundice, vomiting and diarrhea, infantile malnutrition and edema, habitual constipation and malignant boils and so on [2]. The chemical components of $C$. mimosoides include anthraquinones, flavonoids, sterols, etc. [3]. Domestic and foreign studies on the medicinal activity of $C$. mimosoides are mainly focused on its hepatoprotective effect. Some studies suggest that the compounds of anthraquinone in $C$. mimosoides have strong inhibitory effect on lipase, which can prevent and improve body obesity, liver hypertrophy and hypertriglyceridemia caused by high fat diet $[4,5]$. Furthermore, a series of studies have found that the active substances extracted from $C$. mimosoides can protect liver tissue by lowering lipid, inhibiting liver fibrosis and enhancing anti-oxidation [6, 7, 8]. The serum containing the active components of $C$. mimosoides has a protective effect on liver cell injury [9].

Because of its high medicinal value, $C$. mimosoides is in great demand on the market. However, due to the low seed germination rate, long growth cycle, lack of highquality germplasm resources and other problems in the cultivation process, the yield and quality of $C$. mimosoides are difficult to meet the increasing demand of the market. Therefore, this study intends to establish a tissue culture regeneration system for shortening the growth cycle and increasing the yield of $C$. mimosoides, which will provide the early foundation for expanding the planting area of $C$. mimosoides. It also provides raw material for the further analysis of biochemical activities and lays a foundation for applied basic research of liver protection.

\section{Materials and Methods}

\subsection{Plant materials}

In this study, the seeds of $C$. mimosoides were collected from Yinna Mountain (at 24 degrees north and 116 degrees longitude), Meizhou City, Guangdong Province in China.

\subsection{Experimental reagents}

The main reagents used in this study were 6-BA (6benzylamino purine), IBA (indolebutyric acid), NAA (naphthalene acetic acid), sucrose, inositol and agar powder, which were purchased from Beijing Solarbio Science \& Technology Co., Ltd.

\footnotetext{
* Corresponding author: yyali198622@163.com
} 


\subsection{Culture conditions}

1/2MS medium [10] supplemented with $30 \mathrm{~g} / \mathrm{L}$ sucrose and $8 \mathrm{~g} / \mathrm{L}$ agar was served as the basic medium. The $\mathrm{pH}$ value of the medium was adjusted to 5.8 , and the medium was placed in autoclave under conditions of $121^{\circ} \mathrm{C}$ and $0.1 \mathrm{MPa}$ for sterilization for $20 \mathrm{~min}$. The culture conditions of the incubator were set to adjust light at $12 \mathrm{~h}$, light intensity at 2000 2500 lx, humidity at $80 \%$, and temperature at $22^{\circ} \mathrm{C}$.

\subsection{Experimental methods}

\subsubsection{Germination of seeds}

The C. mimosoides seeds were soaked in water at $80^{\circ} \mathrm{C}$ for 5 minutes, washed firstly with $70 \%$ ethanol for 2-3 times and then with 5\% $\mathrm{NaClO}$ for 5-10 minutes, finally with sterile distilled water for 3 times. The sterilized seeds were inoculated on 1/2MS medium for 8 days of culture. Young leaves (size with $0.5 \mathrm{~cm} \times 0.5 \mathrm{~cm}$ squares) were taken from the asepsis seedlings as explants.

\subsubsection{Callus and adventitious bud induction}

The young leaf explants were inoculated horizontally on 1/2MS medium contained $2.0 \mathrm{mg} / \mathrm{L}$ 6-BA and different concentrations of NAA $(0,0.5$ and $1 \mathrm{mg} / \mathrm{L})$ for callus and adventitious bud induction for 80 days of culture.

\subsubsection{Screening of rooting medium}

The regeneration buds (longer than $1 \mathrm{~cm}$ ) were vertically inoculated on $1 / 2 \mathrm{MS}$ medium supplemented with different concentrations of IBA $(0,0.5$ and $1.0 \mathrm{mg} / \mathrm{L})$ and NAA $(0,0.1,0.2$ and $0.5 \mathrm{mg} / \mathrm{L})$ respectively for rooting for 20 days.

\subsubsection{Data analysis}

The induction rate of callus $=$ (number of explants with callus/total number of inoculated explants) $\times 100 \%$; The induction rate of adventitious bud $=$ (number of explants with buds/total number of inoculated explants) $\times 100 \%$; Rooting coefficient $=$ (number of roots/number of root explants $) \times 100 \%$; Rooting rate $=$ (number of rooting shoots/number of inoculated shoots) $\times 100 \%$. The data was analysed by the software SPSS 22.0 and conducted with Duncan multiple comparisons $(P \leqslant 0.05)$. And significant difference was represented by different letters.

\section{Results}

\subsection{Effects of NAA on the induction of callus and adventitious bud}

For the purpose of studying the effect of NAA on callus formation and adventitious bud induction from the young leaf explants, which were inoculated on basal medium supplemented with different concentrations of NAA for 80 days of culture. The results showed that the maximum callus induction rate $(98.5 \%)$ and adventitious shoot regeneration rate $(60 \%)$ were gained when the concentration of NAA was at $0.5 \mathrm{mg} / \mathrm{L}$, while the regeneration effect would be restrained with continuing to increase NAA concentration. These results suggested that NAA had positive effect on improving callus formation and adventitious bud regeneration, and the optimal concentration of NAA was $0.5 \mathrm{mg} / \mathrm{L}$.

Table 1. Results of NAA on the induction of callus and adventitious bud

\begin{tabular}{|c|c|c|}
\hline $\begin{array}{c}\text { Concentrations of } \\
\text { NAA (mg/L) }\end{array}$ & $\begin{array}{c}\text { Callus } \\
\text { induction rate } \\
(\%)\end{array}$ & $\begin{array}{c}\text { Induction rate } \\
\text { of adventitious } \\
\text { bud (\%) }\end{array}$ \\
\hline 0 & $81.1 \pm 5.1 \mathrm{~b}$ & $33.3 \pm 6.7 \mathrm{~b}$ \\
\hline 0.5 & $98.5 \pm 2.0 \mathrm{a}$ & $60.0 \pm 11.5 \mathrm{a}$ \\
\hline 1 & $93.7 \pm 7.5 \mathrm{ab}$ & $6.67 \pm 0.1 \mathrm{c}$ \\
\hline
\end{tabular}

Note: Different letters after the data indicated significant differences.

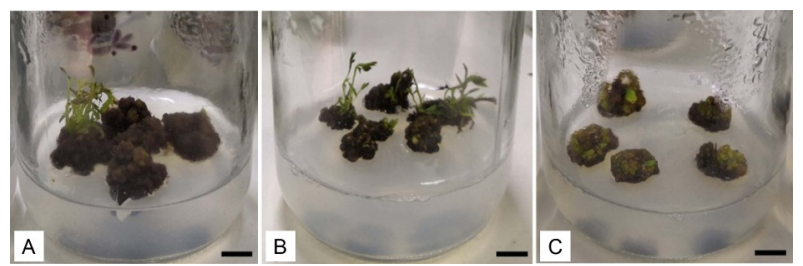

Figure 1. Effects of NAA on the induction of callus and adventitious bud in $C$. mimosoides

Young leaf explants were inoculated on $1 / 2 \mathrm{MS}$ medium contained $2.0 \mathrm{mg} / \mathrm{L}$ 6-BA and A: $0 \mathrm{mg} / \mathrm{L}, \mathrm{B}: 0.5 \mathrm{mg} / \mathrm{L}, \mathrm{C}: 1$ $\mathrm{mg} / \mathrm{L}$ NAA for induction of callus and adventitious bud in $C$. mimosoides for 80 days. (Bars $=1 \mathrm{~cm}$ )

\subsection{Influences of IBA and NAA on rooting of regeneration shoots}

In order to investigate the effect of IBA and NAA on the rooting effect of the regeneration shoots, which were placed into $1 / 2 \mathrm{MS}$ medium contained various concentrations of IBA and NAA for 20 days of culture. The results indicated that IBA could not effectively promote the rooting of $C$. mimosoides regeneration shoots, and with the increasing of IBA concentration, the rooting efficiency of shoots decreased gradually (Table 3 ). The study also found that NAA had a certain effect on the rooting of shoots. Although the number of roots increased, the rooting rate would gradually reduce with the increasing of NAA concentration (Table 4, Figure 2). Therefore, $1 / 2 \mathrm{MS}$ medium without IBA or NAA was the most suitable medium for rooting induction. 
Table 2. Results of different concentration of IBA on rooting of regeneration shoots

\begin{tabular}{|c|c|c|}
\hline $\begin{array}{c}\text { Concentrations of } \\
\text { IBA (mg/L) }\end{array}$ & $\begin{array}{c}\text { Rooting } \\
\text { coefficient }\end{array}$ & $\begin{array}{c}\text { Rooting rate } \\
(\%)\end{array}$ \\
\hline 0 & $5.2 \pm 0.4 \mathrm{a}$ & $96.7 \pm 5.0 \mathrm{a}$ \\
\hline 0.5 & $2.8 \pm 1.6 \mathrm{~b}$ & $80 \pm 8.7 \mathrm{~b}$ \\
\hline 1 & $0.8 \pm 1.0 \mathrm{~b}$ & $16.7 \pm 3.9 \mathrm{c}$ \\
\hline
\end{tabular}

Note: Different letters after the data indicated significant differences.

Table 3. Effects of various concentration of NAA on rooting of regeneration shoots

\begin{tabular}{|c|c|c|}
\hline $\begin{array}{c}\text { Concentrations of } \\
\text { NAA (mg/L) }\end{array}$ & $\begin{array}{c}\text { Rooting } \\
\text { coefficient }\end{array}$ & $\begin{array}{c}\text { Rooting rate } \\
(\%)\end{array}$ \\
\hline 0 & $3.3 \pm 0.8 \mathrm{~b}$ & $93.8 \pm 2.4 \mathrm{a}$ \\
\hline 0.1 & $4.0 \pm 1.6 \mathrm{ab}$ & $86.1 \pm 8.3 \mathrm{ab}$ \\
\hline 0.2 & $9.0 \pm 1.0 \mathrm{a}$ & $79.2 \pm 5.1 \mathrm{~b}$ \\
\hline 0.5 & $11.0 \pm 1.0 \mathrm{a}$ & $65.6 \pm 6.9 \mathrm{~b}$ \\
\hline
\end{tabular}

Note: Different letters after the data indicated significant differences.

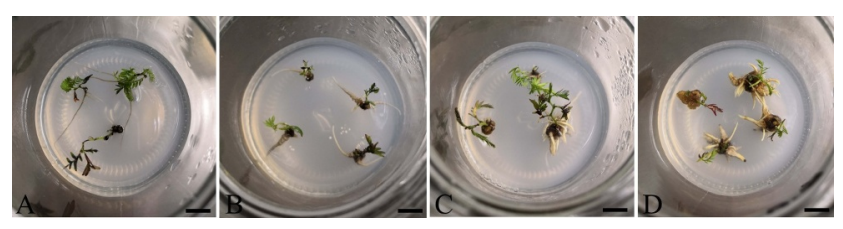

Figure 2. Effects of NAA on rooting of regeneration shoots in C. mimosoides

Regenerated shoots were inoculated on $1 / 2 \mathrm{MS}$ medium supplemented with A: $0 \mathrm{mg} / \mathrm{L}, \mathrm{B}: 0.1 \mathrm{mg} / \mathrm{L}, \mathrm{C}: 0.2 \mathrm{mg} / \mathrm{L}$, D: $0.5 \mathrm{mg} / \mathrm{L}$ NAA for rooting in C. mimosoides for 20 days. $($ Bars $=1 \mathrm{~cm})$

\section{Discussion}

\subsection{Effects of hormones on the induction of callus and adventitious bud}

Plant hormones are a series of extremely low levels of naturally occurring organic compounds in plants. The interactions among various plant hormone signals regulate the growth and differentiation of plant cells. Plant hormones play an important role in the normal development of plants. NAA is a member of auxin family, while 6-BA is one of the cytokinin species, both of them play an important part in induction of callus formation and adventitious bud regeneration. Our results revealed that both NAA and 6-BA were effective in inducing callus and adventitious bud regeneration. Some studies show that the signaling pathways between auxin and cytokinin influence callus formation and adventitious bud regeneration through different contributing factors [11].

\subsection{Effects of IBA and NAA on rooting of regeneration shoots}

Root is important organs for plant to absorb water and nutrients, which can provide various substances for plant growth and development. It is very important for the establishment of plant tissue culture regeneration system to investigate whether regeneration buds can take root. Therefore, it is very necessary to explore the suitable nutrient content and hormone concentration in the medium for the rooting of regeneration shoots. In this study, it was found that regeneration shoots had the best effect of rooting in 1/2MS medium, while the growth of root was inhibited by the addition of hormones. For example, the induction of adventitious root was restrained after adding different concentrations of IBA in medium. Meanwhile, adding different concentrations of NAA could promote the increasing of number of roots, but the roots became shorter and bulkier, and some callus even grown on the roots and the rooting rate decreased. These results are very similar to some that have been reported [12]. Hence, 1/2MS medium was the most suitable medium for the rooting of adventitious shoots of C. mimosoides in the present study.

Application of the established plant regeneration system from young leaf explants of $C$. mimosoides in this study, the incubation time of the plant could be reduced, and the yield of plant material might be increased. However, there are still the following problems in the development of $C$. mimosoides industry, which are worth further discussion. Firstly, the addition of exogenous hormones may cause changes in the ratio and level of endogenous hormones, so as to further regulate the growth of cultures. Although the effect of adding exogenous hormones in the tissue culture of $C$. mimosoides has been clarified in this study, the mechanism of action between various hormones is still unclear. Therefore, the investigation of the physiological mechanism of endogenous hormones in the tissue culture process of $C$. mimosoides will provide a theoretical basis for the use of exogenous hormone concentrations and different hormone combinations in the future, and also provide reference for the protection of medicinal plant resources of Cassia and industrial seedling cultivation. Secondly, the quality of tissue culture seedlings must be further improved to provide raw materials for the largescale artificial planting of $C$. mimosoides. On the basis of tissue culture combined with modern biological breeding technology, excellent varieties with good quality and strong disease resistance will be cultivated, and scientific and standardized planting will be carried out to achieve greater economic benefits. 


\section{Conclusion}

In this study, a method for plant regeneration of young leaf explants from aseptic seedlings of Cassia mimosoides was established successfully. Our preliminary results suggested that when the explants were placed onto the $1 / 2 \mathrm{MS}$ medium supplemented with $2.0 \mathrm{mg} / \mathrm{L}$ 6-BA and $0.5 \mathrm{mg} / \mathrm{L} \mathrm{NAA}$, high callus induction rate and good growth status of adventitious bud, and the highest number of buds were gained. Further research results revealed that IBA could not promote root formation effectively, but the roots could be induced by NAA. Howerer, although the rooting of buds could be induced when adventitious shoots were inoculated into $1 / 2 \mathrm{MS}$ medium contained $0.5 \mathrm{mg} / \mathrm{L}$ NAA, only poor rooting effect could be obtained. In conclusion, the best medium for induction of adventitious bud regeneration using young leaf as explants in $C$. mimosoides was $1 / 2 \mathrm{MS}$ medium supplemented with 2.0 $\mathrm{mg} / \mathrm{L}$ 6-BA and $0.5 \mathrm{mg} / \mathrm{L} \mathrm{NAA}$, and the optimum rooting medium was $1 / 2 \mathrm{MS}$.

\section{Acknowledgement}

This study was supported by Science and Technology Program of Guangdong Province: Guangdong Provincial Key Laboratory of Conservation and Precision Utilization of Characteristic Agricultural Resources in Mountainous Areas (2020B121201013), Project of Traditional Chinese Medicine Bureau of Guangdong Province (20202211), the College Students Innovation and Entrepreneurship Training Program (S201910582106), Allowance Adjustment on Medical Care and Insurance in 2019 (Sustainable Development of Chinese Medicine) National Investigation on Chinese Phytomedicine ( funding: 2019 No.39).

\section{References}

1. J.D. Zhang, S.P. Wen, Y.S. Fan. Inhibitive effects of extract of Cassia mimosoides Linn on dimethylnitrosamine-induced hepatic fobrosis in rats. Lishizhen Med. Mate. Med. Res. 20, 2879-2881 (2009)

2. L.R. Song, X. Hong, X. L. Ding, et al. Dictionary of modern Chinese medicine. Beijing: People Med. Publish. House, 184, 192-195 (2001)

3. D.F. Han, C.L. Du, X.J. Wang. Chemical constituents of Cassia mimosoides. Chin. J. Exp. Trad. Med. Form. 22, 78-81 ( 2016)

4. S.S.N. Subramanian, S. Subramanian, N.S. Sankara. Chemical examination of the leaves of Cassia mimosoides. Ind. J. Pharm. 31, 110-111 (1969)

5. S.S.N. Subramanian. Chemical components of the roots and seeds of Cassia mimosoides. Ind. J. Pharm. 32(3): 70-71(1970)

6. C.P. Shen, Q.H. Du, Y.Y. Zhang, et al. Experimental study on lipid-regulating effect of water extract of Cassia mimosoides on hyperlipidemia rats. J. Chin. Med. Mate. 38, 21692171 (2015)

7. W. Zhang, J.D. Zhang, R.L. Li, et al. Experimental study of alcohol extract of Cassia mimosoides on inhibition of liver fibrosis induced by dimethylnitrosamine in rats. New Dru. Chin. Mate. Med. Clin. Pharma. 20, 308-312 (2009)

8. Z.W. Liu, W. Kuang, C. Zhang, et al. The antioxidant activities of Cassia mimosoides extracts. Food Sci. Technol. 39, 225-228 (2014)

9. L. Huang, Y.S. Fu, C.X. Zhu, et al. Study on the protective effect of drug serum of Cassia mimosoides on hydrogen peroxide-induced hepatocyte injury. J. Liaoning Univ. Trad. Chin. Med. 19, 45-47 (2017)

10. T. Murashige, F, Skoog. A revised medium for rapid growth and bioassays with tobacco tissue cultures. Physiol Plant. 15, 473-479 (1962)

11. M. Ikeuchi, K. Sugimoto, A. Iwase. Plant callus: mechanisms of induction and repression. Plant Cell. 25, 3159-73 (2013)

12. Z.P. Wu, Y.K. Gao, M. Fan, et al. Construction of regeneration and transformation system of chrysanthemum 'Jinbudiao'. Mol. Plant Breed. 18, 150-158 (2020) 